\title{
Labour force participation among patients with rheumatoid arthritis
}

\author{
Astrid M J Chorus, Harald S Miedema, Cees J Wevers, Sjef van der Linden
}

\begin{abstract}
Objectives-To assess work history and labour force participation among patients with rheumatoid arthritis (RA) in the Netherlands.

Methods-A random sample of 1056 patients with RA aged 16-59 years from 17 rheumatology practices in the Netherlands was examined. Data on disease status and outcome were obtained by a questionnaire including standardised instruments, such as the Rapid Assessment of Disease Activity in Rheumatology (RADAR) and RAND-36 questionnaires. Labour force participation was defined as having a paid job.

Results-Of the study group with a mean disease duration of 12 years, $35.7 \%$ held a paid job (men $56.7 \%$; women $27.7 \%$ ). When standardised for age, sex, and educational level, the labour force participation of patients with RA was $61.2 \%$ compared with $65.5 \%$ for the general population, which was not statistically significant. Disease duration of six years and more was negatively associated with labour force participation.

Conclusions-After controlling for the confounding effects of age, sex, and education, the labour force participation of patients with RA in the Netherlands is only slightly lower than that of the general population.

(Ann Rheum Dis 2000;59:549-554)
\end{abstract}

Health, TNO

Prevention and

Health, Leiden,

The Netherlands

A M J Chorus

Health Research and

Development Council,

The Hague,

The Netherlands

H S Miedema

TNO Labour,

Hoofddorp,

The Netherlands

C J Wevers

Department of

Rheumatology,

University Hospital

Maastricht,

The Netherlands

$S$ van der Linden

Correspondence to:

A M J Chorus MSc, TNO

Prevention and Health, $\mathrm{PO}$

Box 2215, 2301 CE Leiden,

The Netherlands

Email:

AMJ.Chorus@pg.tno.nl

Accepted for publication 24 January 2000 to time within one single patient. ${ }^{78}$ Its major distinctive feature is chronic, symmetrical, and erosive synovitis of peripheral joints, including hands and feet. Although the severity of the joint disease may fluctuate over time, the most common outcome of established disease is progressive development of various degrees of joint destruction, deformity, immobility, pain, fatigue, depression, and anxiety.

Rheumatoid arthritis has a multidimensional impact on peoples' lives, which can result in handicaps and disabilities, such as difficulties in performing activities of daily life, and work loss. ${ }^{9-11}$ Labour force participation (that is, the proportion of people having a paid job) was found to be reduced among patients with RA, even at an early stage of disease, ranging from $40 \%$ to $50 \%{ }^{1}{ }^{12}$

To assess work history and labour force participation of patients with RA, we conducted a cross sectional study among a representative sample of Dutch patients with RA attending rheumatology outpatient clinics.

\section{Methods}

SAMPLE SELECTION

The source study group was derived from the nationwide Standardised Diagnosis Register of Rheumatic Diseases (SDR), a representative database of outpatients visiting a rheumatologist. ${ }^{13}$ The SDR database contains information on the patient population of $80 \%$ of all rheumatologists working in the Netherlands. In the SDR, diagnoses of visiting patients are recorded every year by rheumatologists. Participating rheumatologists are instructed to apply the 1987 classification criteria of the ACR. ${ }^{3}$ The SDR provides an option of registering the seven items of the ACR criteria explicitly, which was done by some of the participants. A geographically representative sample of 35 rheumatologists (37\% of all SDR rheumatologists), working in 17 practices (52\% of all SDR practices) throughout the Netherlands was included in this study. From these practices, a random sample of patients diagnosed as having RA, aged $16-59$ years in 1996 and registered in 1994 in the SDR, was selected. Because RA is more prevalent in women and in older people, a rated sampling procedure was followed to obtain sufficient numbers of male patients and of younger patients. Therefore, the sampling procedure for men was inclusion of all patients aged 16-50, and a random selection of $75 \%$ of the patients aged 51-59. For the women all patients aged 16-40 were included, and a random selection of $50 \%$ of the patients aged $41-50$ and of $40 \%$ of those aged 51-59. In total, 1693 patients with RA were selected for our study (635 men, 1058 women).

All patients were sent a letter by their own rheumatologist with information about the study on "Abilities of persons with rheumatoid 
arthritis". They were invited to indicate their willingness to participate by sending a completed form to the TNO Institute addressing two questions to obtain information on the current work status. Patients not willing to participate were kindly asked to return this form anonymously and to give reasons for nonparticipation. Only 5\% returned a negative response form, of whom fewer than a quarter gave any reason for non-participation. These methods were approved by the medical ethical committee of TNO and were in accordance with the privacy law in the Netherlands.

After two reminders, a total of 1056 patients with RA ( $62 \%$ of the initial cohort) returned a completed questionnaire. Those patients are called the participants. Patients who did not respond or who responded negatively are called the non-participants. Seventy three per cent of the participants were female with a mean age of 49.0. Age and sex did not differ significantly between participants and non-participants (73\% of the non-participants were female with a mean age of 49.1). The SDR data showed that $53 \%$ of both the participants and nonparticipants satisfied four or more of the ACR criteria. $^{3}$ For the remaining $47 \%$ of both the participants and the non-participants information on ACR criteria was lacking or incomplete in the SDR. To validate the diagnosis RA, medical files of a random sample of $20 \%$ (201 patients) of the participating patients were checked by rheumatologists for the presence of ACR criteria at the time of the study. It was found that $152(76 \%)$ had four or more of the criteria and $165(82 \%)$ were currently using disease modifying antirheumatic drugs.

DATA COLLECTION

A self administered questionnaire covering sociodemographics (age, sex, highest attained level of education, type of income), disease characteristics, functional abilities in daily life, general health, and current work situation was completed.

\section{Disease characteristics}

Disease activity was assessed by a Dutch translation of the Rapid Assessment of Disease Activity in Rheumatology (RADAR), a brief self administered questionnaire, designed to provide valid, interpretable clinical information of patients with RA. ${ }^{14}$ The forward and backward translated RADAR questionnaire contains five questions relevant to disease activity (arthritis activity today; arthritis activity over the past six months; arthritis pain today; duration of morning stiffness; and joint tenderness today). From these five questions an index was calculated, the so-called Rheumatoid Arthritis Disease Activity Index (RADAI). This index was found to be a highly reliable and valid self administered measure of disease activity for clinical, health services, and epidemiological research. ${ }^{15}$ The scores of RADAI may range from 0 to 10 . Higher scores indicate more disease activity.

Patients were also asked about their age at the time RA was diagnosed. To assess disease duration, age at diagnosis of RA was subtracted from the age at time of completing the questionnaire.

Work history and labour force participation Work history was assessed on the basis of two variables. Respondents indicated whether or not they had a paid job at the time of diagnosis, and indicated what their current work status was (whether they had a paid job at the time of the study, they had left the labour force (because of RA or any other reason), or had never had a paid job). Labour force participation was defined as having a paid job at the time of the study.

\section{Activities in daily life}

To assess functional abilities in daily life a validated Dutch version of the Health Assessment Questionnaire ${ }^{16}$ was used, containing 20 items addressing eight dimensions of activities in daily life (dressing and grooming; arising; eating; walking; hygiene; reaching; gripping; other household activities). Each item is scored $0-3$ ( $0=$ without any difficulty; $1=$ with some difficulty; 2 = with much difficulty or with help from another person or with a device; $3=$ not able to do). An overall score is calculated as the mean score of the eight scores obtained for the dimensions separately.

\section{Quality of life}

Information about health related quality of life was obtained by a validated Dutch translation of the RAND-36, ${ }^{17}{ }^{18}$ a standardised questionnaire referring to eight dimensions (physical functioning; social functioning; role impairment due to physical functioning; role impairment due to social functioning; mental health; bodily pain; vitality; and general health), and changes in health over the past year. The RAND-36 is quite similar to the internationally widely used SF-36, for which a Dutch translation had not yet been validated at the time of our study. The scores for the separate dimensions of the RAND-36 can vary from 0 to 100 . Lower scores indicate worse outcomes.

\section{DATA ANALYSIS}

Work history of the total study group was examined to give an overall impression of the working career of people with RA. Furthermore, patient characteristics of the study group were analysed both for working and nonworking patients. Statistical differences in means and proportions were tested with the CSAMPLE module of the statistical package Epi Info, version $6.02 .{ }^{19}$ The CSAMPLE module computes means or proportions with standard errors and 95\% confidence limits for studies in which the data did not come from a simple random sample.

Next, labour force participation of patients with RA was studied for the whole group with RA and stratified for age, sex, and educational level. The highest attained educational level was separated into three categories: primary, secondary, and vocational colleges/university level. Age, sex, and educational level are well known determinants of labour force participation. Therefore, to enable better comparison 
with reference data of labour force participation for the general Dutch population, we adjusted the age-sex-educational level distribution in the study group to the distribution in the general Dutch population by using the direct standardisation method. ${ }^{20}$

To study the independent effect of disease duration on the labour force participation, agesex-educational level specific proportions of having work in our study group were compared with those in the general population by using an indirect method of standardisation (based on the method for obtaining the Standardised Morbidity Ratio and its variance). Therefore, we calculated for our study group ratios of the observed (O) and expected (E) number of working people for evenly spaced five-year categories of disease duration. Because of our study design the first category ranges from two to five years of disease duration. Expected

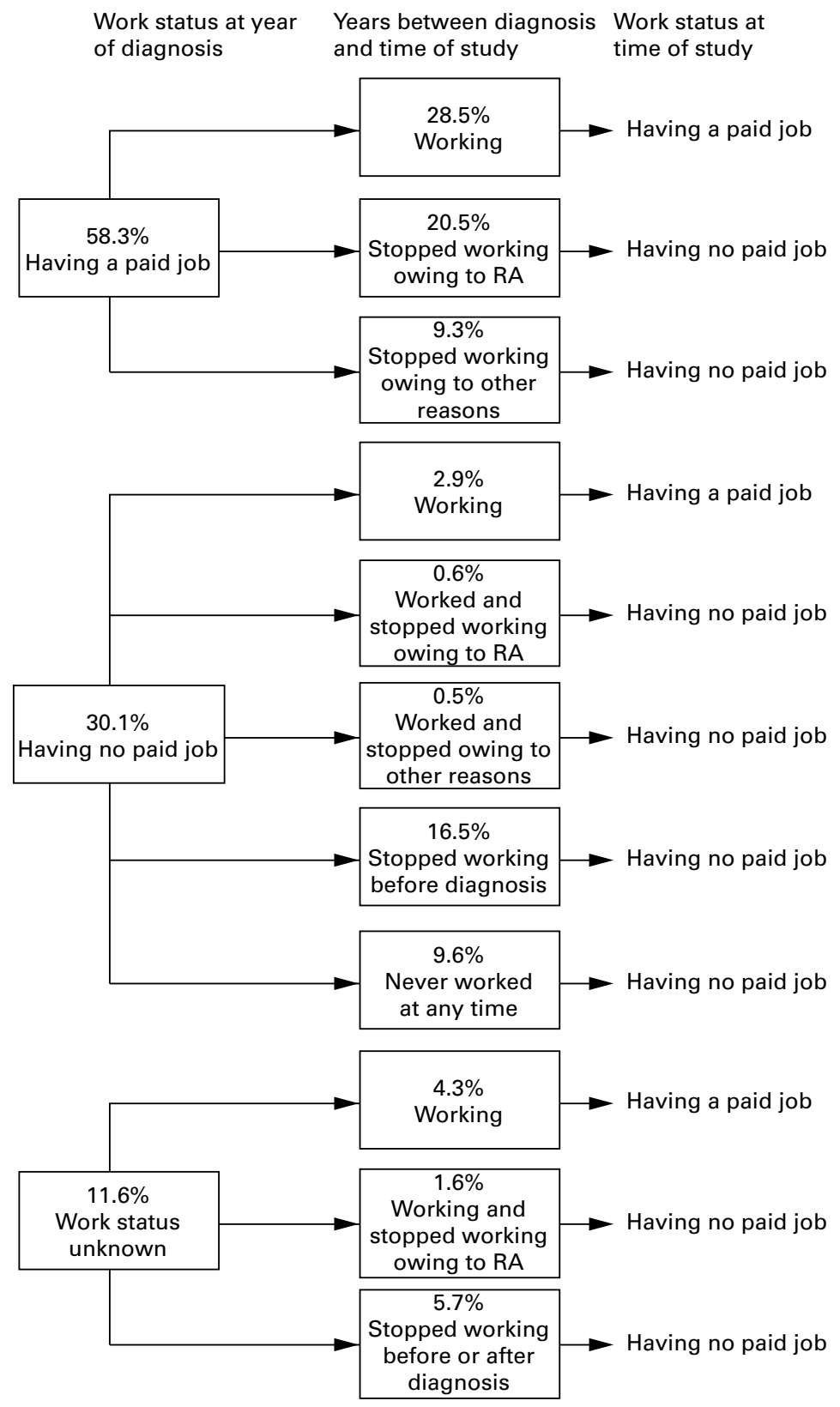

Figure 1 Work history of 1056 patients with rheumatoid arthritis (RA). numbers of labour force participation were computed with age, sex, and educational level labour force participation reference data for the general Dutch population. ${ }^{20}$ The $\mathrm{O} / \mathrm{E}$ ratio is the ratio of the observed number of patients with RA with a paid job to the number expected. This ratio could be interpreted as the relative chance of patients with RA having a paid job compared with the general Dutch population, adjusted for age, sex, and educational level. A rate ratio of 1.0 indicates that the proportion of patients with RA working is the same as that in the general population. A rate ratio of less than 1.0 indicates that the proportion of patients with RA working is less than that in the general population, and a rate ratio of more than 1.0 indicates that the proportion of patients with RA working is more than that in the general population. To examine statistically significant differences between the group with RA and the general population we obtained the variances of the $\mathrm{O} / \mathrm{E}$ ratios, and estimated their $95 \%$ confidence intervals $(\mathrm{O} /$ $\mathrm{E} \pm 1.96 \times \operatorname{var}(\mathrm{O} / \mathrm{E}))$. If a rate ratio of 1.0 is included in the interval, this implies that the estimate is not statistically significant at the $0.05 \alpha$ level. ${ }^{21}{ }^{22}$ These analyses were performed with the statistical package SPSS for Windows, release $6.1 .3 .^{23}$

\section{Results}

Figure 1 presents the work history of the patients with RA from the year of diagnosis until the time of study in 1996. At the time of diagnosis of RA, the work situation was unknown for $11.6 \%$ patients. Overall, $68.2 \%$ of the study group had a paid job, at least temporarily, at some time after being diagnosed with RA. In 1996, 35.7\% still held a paid job, 54.7\% of the total population stopped working, of whom $40 \%$ stopped working because of RA (this is $22.7 \%$ of the total group with RA), and $9.6 \%$ had never had a paid job. The mean disease duration of the population was 11.9 years, varying from two years to 32 . The mean duration of working after being diagnosed with RA was 7.2 years, varying from 0 years to 32 .

Table 1 presents patient characteristics, disease status, and outcome of the total study group, and of the working and non-working study group.

It was found that on average patients with RA who were younger, male, or more highly educated were more likely to be working $(p<0.05)$. In this group of patients RA was more recently diagnosed and disease activity was significantly less than among patients without a paid job. Working patients had significantly fewer disabilities and a better quality of life than patients who did not worktheir physical functioning was better and their role impairment was less.

The crude labour force participation of patients with RA was $35.7 \%(56.7 \%$ in men and $27.7 \%$ in women) (table 2). To assess the labour market position of patients with RA in the Netherlands we compared our study group with the general Dutch population of working age (16-59 years). Our study group had a higher mean age and contained more women 


\begin{tabular}{|c|c|c|c|}
\hline & $\begin{array}{l}\text { Total RA population } \\
(n=1056)\end{array}$ & $\begin{array}{l}\text { Patients with } R A \text { with a } \\
\text { paid job }(35.7 \%)\end{array}$ & $\begin{array}{l}\text { Patients with } R A \text { without a } \\
\text { paid job }(64.3 \%)\end{array}$ \\
\hline Age (years), mean $(95 \% \mathrm{CI})$ & $49.0(48.5$ to 49.5$)$ & $45.8(45.0$ to 46.7$)$ & $50.7(50.1$ to 51.3$)$ \\
\hline Sex, $\%$ men $(95 \%$ CI $)$ & $27.7(25.2$ to 30.1$)$ & 43.9 (39.2 to 48.7$)$ & $18.6(15.8$ to 21.4$)$ \\
\hline High vocational colleges/university, \% (95\% CI) & $12.1(10.1$ to 14.2$)$ & $20.2(16.2$ to 24.1$)$ & $7.5(5.4$ to 9.8$)$ \\
\hline Disease duration (years), mean $(95 \% \mathrm{CI})$ & $11.9(11.4$ to 12.5$)$ & $9.9(9.2$ to 10.6$)$ & $12.9(12.3$ to 13.8$)$ \\
\hline Disease activity ( RADAI, $0-10)$, mean (95\% CI) & $4.2(4.1$ to 4.4$)$ & $3.5(3.3$ to 3.7$)$ & $4.6(4.5$ to 4.8$)$ \\
\hline Disability score (HAQ, $0-3)$, mean $(95 \%$ CI $)$ & $1.00(0.96$ to 1.05$)$ & $0.7(0.60$ to 0.72$)$ & $1.2(1.13$ to 1.26$)$ \\
\hline \multicolumn{4}{|l|}{ Quality of life (RAND-36, 0-100), mean (95\% CI) } \\
\hline Physical functioning & $49.2(47.2$ to 50.8$)$ & $62.2(59.7$ to 64.6$)$ & $42.0(40.0$ to 44.1$)$ \\
\hline Role impairment due to physical functioning & 44.5 (41.9 to 47.3$)$ & $60.0(55.7$ to 64.2$)$ & $34.9(31.1$ to 38.7$)$ \\
\hline Social functioning & $72.5(70.9$ to 74.0$)$ & $80.2(78.1$ to 82.2$)$ & $68.1(66.1$ to 70.2$)$ \\
\hline Role impairment due to social functioning & $74.6(71.9$ to 77.3$)$ & $84.9(81.6$ to 88.1$)$ & $68.4(64.5$ to 72.3$)$ \\
\hline Mental health & $72.2(71.0$ to 73.4$)$ & $77.0(75.3$ to 78.6$)$ & $69.5(68.0$ to 71.1$)$ \\
\hline Reduced vitality & $53.4(52.2$ to 54.7$)$ & $58.3(56.5$ to 60.1$)$ & $50.7(49.0$ to 52.4$)$ \\
\hline Painlessness & $55.7(54.3$ to 57.0$)$ & $63.7(61.7$ to 65.7$)$ & $51.2(49.4$ to 53.0$)$ \\
\hline General health & $49.7(48.4$ to 51.1$)$ & $55.3(53.3$ to 57.2$)$ & $46.6(44.8$ to 48.4$)$ \\
\hline Changes in health over the past year & $38.8(37.6$ to 39.9$)$ & $41.6(39.9$ to 43.4$)$ & 37.1 ( 35.6 to 38.7$)$ \\
\hline
\end{tabular}

Table 2 Labour force participation (LFP) and 95\% confidence intervals (CI) among 1056 patients with RA compared with reference data from the general Dutch population ${ }^{20}$

\begin{tabular}{|c|c|c|c|c|c|}
\hline Highest educational level & $\begin{array}{l}\text { Age category } \\
\text { (years) }\end{array}$ & $\begin{array}{l}\text { LFP rate of men with } \\
R A(95 \% \mathrm{CI})\end{array}$ & $\begin{array}{l}\text { LFP rate of general } \\
\text { male population }\end{array}$ & $\begin{array}{l}\text { LFP rate of women } \\
\text { with } R A(95 \% \mathrm{CI})\end{array}$ & $\begin{array}{l}\text { LFP rate of general } \\
\text { female population }\end{array}$ \\
\hline Overall (crude) & All & 56.7 (51.8 to 61.7$)$ & & 27.7 (24.3 to 31.2$)$ & \\
\hline Overall (standardised) & All & 74.3 (64.3 to 84.3$)$ & 81.0 & $47.6(43.2$ to 52.1$)$ & 50.1 \\
\hline Primary school & $\begin{array}{l}20-29 \\
30-39 \\
40-49 \\
50-59\end{array}$ & $\begin{array}{l}\mathbf{0} \\
77.8(50.9 \text { to } 100) \\
\mathbf{5 5 . 2}(\mathbf{4 5 . 2} \text { to } \mathbf{6 5 . 0}) \\
\mathbf{3 3 . 7}(\mathbf{2 8 . 2} \text { to } \mathbf{3 9 . 2})\end{array}$ & $\begin{array}{l}\mathbf{6 6 . 3} \\
71.6 \\
\mathbf{7 0 . 4} \\
\mathbf{5 5 . 1}\end{array}$ & $\begin{array}{l}22.2(0.0 \text { to } 49.1) \\
20.0(6.5 \text { to } 33.5) \\
23.9(16.6 \text { to } 31.2) \\
12.4(8.3 \text { to } 16.5)\end{array}$ & $\begin{array}{l}26.6 \\
27.4 \\
28.7 \\
16.5\end{array}$ \\
\hline Secondary school & $\begin{array}{l}20-29 \\
30-39 \\
40-49 \\
50-59\end{array}$ & $\begin{array}{l}75.0(32.7 \text { to } 100) \\
84.2(68.3 \text { to } 100) \\
85.5(77.3 \text { to } 93.7) \\
\mathbf{5 9 . 3}(\mathbf{5 1 . 0} \text { to } \mathbf{6 7 . 5})\end{array}$ & $\begin{array}{l}76.2 \\
92.0 \\
90.0 \\
71.1\end{array}$ & $\begin{array}{l}78.8(65.3 \text { to } 92.3) \\
45.2(36.2 \text { to } 54.2) \\
46.3(37.9 \text { to } 54.7) \\
\mathbf{1 2 . 4}(\mathbf{5 . 7} \text { to } \mathbf{1 9 . 1})\end{array}$ & $\begin{array}{l}65.7 \\
50.2 \\
47.6 \\
27.7\end{array}$ \\
\hline $\begin{array}{l}\text { High vocational } \\
\text { colleges/university }\end{array}$ & $\begin{array}{l}20-29 \\
30-39 \\
40-49 \\
50-59\end{array}$ & $\begin{array}{l}50.0(0.0 \text { to } 100) \\
80.0(45.1 \text { to } 100) \\
89.5(76.7 \text { to } 100) \\
78.8(67.6 \text { to } 90.0)\end{array}$ & $\begin{array}{l}71.1 \\
94.0 \\
92.6 \\
81.7\end{array}$ & $\begin{array}{l}66.7(29.9 \text { to } 100) \\
75.0(59.5 \text { to } 90.5) \\
\mathbf{5 4 . 8}(\mathbf{4 0 . 9} \text { to } \mathbf{6 8 . 7}) \\
\mathbf{3 4 . 6}(\mathbf{1 6 . 4} \text { to } \mathbf{5 2 . 8})\end{array}$ & $\begin{array}{l}68.6 \\
78.9 \\
\mathbf{7 2 . 1} \\
\mathbf{5 4 . 9}\end{array}$ \\
\hline
\end{tabular}

and fewer higher educated people. This was to be expected because the peak incidence of RA occurs between the ages of 40 and 60, and because of the higher prevalence of RA in women than in men.

When the overall standardised labour force participation rates for male and female patients with RA were calculated it was shown that the sex-specific labour force participation rates for those with RA were not statistically significantly lower than the same rates for the general Dutch population. Therefore, the overall standardised labour force participation of the group with RA was not significantly different from that of the general Dutch population. The overall standardised labour force participation of RA was $61.2 \%$ (95\% CI $55.7 \%$ to $66.7 \%$ )

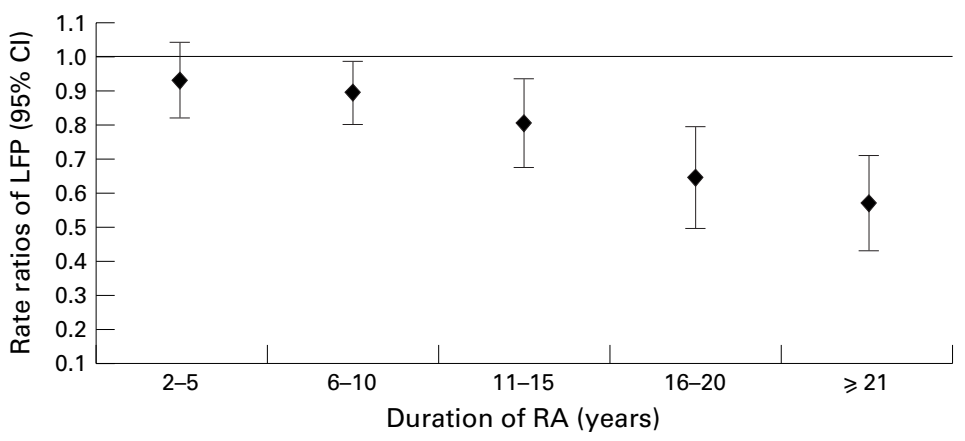

Figure 2 Relation between labour force participation (LFP) and disease duration among patients with rheumatoid arthritis ( $R A)$, standardised for age, sex, and educational level, expressed as rate ratios. compared with $65.5 \%$ for the general Dutch population. However, clear differences were seen when educational levels were taken into account.

For patients with RA with a primary level of education, labour force participation was significantly reduced only for men in the age categories 20-29, 40-49, and 50-59 compared with the general population. For both male and female patients with a secondary school level of education, it was found that labour force participation was only significantly reduced in the highest age category. For patients with RA with a high level of education, labour force participation was significantly reduced only for women in the age categories $40-49$ and 50-59.

Figure 2 shows the relation between disease duration and labour force participation in patients with RA as rate ratios and their 95\% CI. It shows that patients with RA with disease duration of six years or more have significantly fewer paid jobs than people in the general Dutch population of the same age, sex, and educational level. The proportion of working people in patients with RA with a disease duration of 6-10 years is 1.1 times less than in the general population, 1.3 times less in patients with a disease duration of 11-15 years, 1.6 times less in patients with disease duration of 16-20 years, and 1.8 times less in patients with disease duration of 21 years or more. 


\section{Discussion}

Our study indicates that the labour force participation of patients with RA in the Netherlands is largely comparable with that of the general population, when confounding effects of age, sex, and educational level are considered. Still, it was found that disease duration of six years and more was negatively associated with labour force participation. In contrast with our study, most other reports on RA and labour force participation deal with groups with a work history and focus merely on early withdrawal from the labour force among patients with recently diagnosed RA, ${ }^{12} 24-26$ except for one. ${ }^{27}$ In this last study, labour force participation was $41 \%$ among patients with RA with a mean disease duration of 12 years, which is consistent with our study. Yelin et al studied labour force participation and disease duration and found that $50 \%$ of patients with RA with some work experience stopped working within a decade after diagnosis, $60 \%$ within 15 years, and $90 \%$ within 30 years. ${ }^{1}$ In the Netherlands Doeglas et al found that $40 \%$ of patients with RA withdrew from the labour force within four years after diagnosis. ${ }^{12}$ Our study shows a lower reduction in labour force participation in relation to disease duration. It should be noted, however, that in our study we also considered patients without a work history, because they potentially can enter the labour force. Moreover, we also controlled for common risk factors of labour force participation, such as age, sex, and education. To compare our labour force participation rates with those for patients with RA in other countries, it is also important to consider other work dynamics, such as the demand for labour, which can fluctuate over time and differ between countries, and the differences in social insurance legislation systems.

Our study has a number of limitations. Firstly, selection bias (non-response bias) might have affected the observed results. To reduce selective response of patients with a paid job, we introduced the study to the patients as a survey of abilities of people diagnosed with RA. After sending two reminders the response rate was $62.4 \%$, which, although not high, is an average rate for studies with postal questionnaires in the Netherlands. A randomised trial of various design and mailing routines for questionnaires in an open population showed even lower response rates $(40-56 \%) .^{28}$ Few non-participating patients indicated a reason for refusing to participate and because of privacy legislation in the Netherlands we could not perform an extensive non-response analysis. When the SDR was examined we found no significant differences of age, sex, and the registration of ACR criteria between participants and non-participants.

Secondly, we only validated the diagnosis for a randomly selected sample of the participating patients with RA (that is, $20 \%$ of the total population). Based on that sample it can be concluded that $75.6 \%$ of the population fulfilled the 1987 ACR criteria. This might seem to be drawback of this study. However, ACR criteria are intended for classification and are not suited for diagnosis. Moreover, it is well known that at one moment patients with RA can satisfy the ACR criteria and no longer satisfy them at another time. This is especially the case in patients with early RA, self limited RA, and patients with slowly progressive RA during a period of low disease activity. ${ }^{29}{ }^{30}$ In addition, all patients were diagnosed as having RA by a rheumatologist, and these patients had difficulties in their social contacts, even when they did not meet the classification criteria. Therefore, we believe that our study group is representative of the clinical RA population in rheumatology practices. On the basis of the SDR, it is estimated that rheumatologists treat $25 \%$ of the total group of patients with RA in the Netherlands. ${ }^{13}$ It is reasonable to assume that patients treated by a rheumatologist have worse disease and a poorer outcome than patients not treated by a rheumatologist. Therefore, we conclude that our results are not representative of the total RA population in the Netherlands. In addition, labour force participation of the total RA population in the Netherlands will be higher than that of the RA population treated by a rheumatologist.

Thirdly, data were collected by a self administered questionnaire, and were not confirmed by objective measures. However, the questionnaire comprised several well validated instruments to assess disease status and outcome. ${ }^{14-18}$ Although the year of diagnosis of RA by a rheumatologist was assessed retrospectively, we believe that this event has such an impact on patients' lives, that it is unlikely that this was substantially and systematically affected in any direction by recall bias.

In summary, this study shows that labour force participation among patients with RA in the Netherlands is not as strongly reduced as is often assumed. To enable comparability between populations it is important to control for the common risk factors age, sex, and educational level.

It should be noted that holding a paid job does not imply that the work situation (working part time, changing jobs) of working patients with RA is comparable with that of the general Dutch working population. A previous study found that for working Dutch patients with RA there were negative influences on their working capabilities, and also on their social participation and household activities. ${ }^{31}$ Other studies have shown that disease related factors, psychosocial as well as work related (such as physical job demand, job autonomy, type of job, and job satisfaction), contribute also to the work ability of patients with RA. ${ }^{125}{ }^{22-35}$

1 Yelin E, Henke C, Epstein W. The work dynamics of the person with rheumatoid arthritis. Arthritis Rheum 1987;30:507-12.

2 Warr P. Work, unemployment and mental health. Oxford: Clarendon Press, 1987

3 Arnett FC, Edworthy SM, Bloch DA, McShane DJ, Fries JF, Cooper NS, et al. The American Rheumatology Association 1987 revised criteria for the classification of rheumatoid arthritis. Arthritis Rheum 1988;31:315-24.

4 Blécourt JJ de. 'Screening' of the population for rheumatic diseases. Ann Rheum Dis 1954;13:338-40.

5 Graaff R de. Rheumatoid arthritis in the Netherlands (De reumatoide arthritis in Nederland). Assen: Van Gorcum, 1962. matoide arthritis in Nederland). Assen: Van Gorcum, 1962 .
Valkenburg HA,van Laar A, Hofman A. Epidemiology of rheumatic diseases in the Netherlands (Epidemiologie van reumatische aandoeningen in Nederland: de omvang van reumatische klachten en aandoeningen in een open Neder- 
landse bevolkingsgroep). In: Rasker JJ, Festen JJM, eds. Reumatologie in perspectief (Van Hoytema cursus). Enschede: Reumatologie in perspectief (Van Hoytem
Technische Hogeschool Twente, 1980.

7 Utsinger PD, Zvaifler NJ, Ehrlich GE. Rheumatoid arthritis, etiology, diagnosis, and treatment. Philadelphia: Lippincott, 1985:1-984

8 Harris ED Jr. Mechanisms of disease: rheumatoid arthritispathophysiology and implications for therapy. $\mathrm{N}$ Engl J Med 1990;322:1277-89.

9 Felts W, Yelin E. The economic impact of the rheumatic diseases in the United States. J Rheumatol 1989;16:86784.

10 Yelin E, Feschbach D, Meenan R, Epstein W. Social problems, services and policy for persons with chronic disease: the case of rheumatoid arthritis. Soc Sci Med 1979;13C:13-20.

$11 \mathrm{Katz}$ PP, Yelin EH. Life activities of persons with rheumatoid arthritis with and without depressive symp-

12 Doeglas D, Suurmeijer T, Krol B, Sandermann R, van Leeuwen M, Rijswijk M van. Work disability in early rheuLeeuwen $M$, Rijswijk M van. Work disability in early
matoid arthritis. Ann Rheum Dis 1995;54:455-60.

13 Miedema HS, van der Linden SM, Rasker JJ, Valkenburg HA. A national database of patients visiting rheumatologists in the Netherlands: the Standard Diagnosis Register of Rheumatic Diseases. A report and preliminary analysis. Br J Rheumatol 1998;37:555-61.

14 Mason JH, Anderson JJ, Meenan RF, Haralson KM, LewisStevens D, Kaine JL. The Rapid Assesment of Disease Activity (RADAR) questionnaire: validity and sensitivity to change of a patient self-report measure of joint count and clinical status. Arthritis Rheum 1992;35:156-62.

15 Stucki G, Liang MH, Stucki S, Brühlmann P, Michel BA. A self-administered rheumatoid arthritis disease activity
index (RADAI) for epidemiologic research. Arthritis Rheum 1995;38:795-8.

16 Bijlsma JWJ, Oude Heuvel CHB, Zaalberg A. Development of the Dutch questionnaire capacities of daily life (VDF) of of the Dutch questionnaire capacities of daily life (VDF) of patients with rheumatoid a
tion Sciences 1990;2:71-4.

17 Brook RJ, Ware JE, Davies-Avery A, Stewart AL, Donald CA, Rogers WH, et al. Overview of adult health status measures fielded in RAND's health insurance study. Med Care 1979; 15:724-35.

18 van der Zee KI, Sandermann R. Het meten van de gezondheidstoestand met de RAND-36: een handleiding. Groningen: Northern Centre for Health Care Research, University of Groningen, 1993.

19 Centers for Disease Control and Prevention/World Health Organisation. Epi Info. Version 6.02. 1994.

20 Statistics Netherlands (CBS). Survey of general population in the working age 1996. The Hague: Statistics Netherlands, 1997.
21 Armitage P, Berry G. Statistical methods in medical research. 2nd ed. Oxford: Blackwell Scientific, 1987.

22 Rothman KJ, Greenland S. Modern epidemiology. 2nd ed. Philidelphia: Lippincott-Raven, 1998

23 SPSS. SPSS for Windows. Release 6.1.3. 1995.

24 Mau W, Bornmann M, Weber H, Weidemann HF, Hecker $\mathrm{H}$, Raspe $\mathrm{HH}$. Prediction of permanent work disability in a follow-up study of early rheumatoid arthritis: results of a follow-up study of early rheumatoid arthritis: results of a 1996;35:652-9.

25 Fex E, Larsson B-M, Nived K, Eberhardt K. Effect of rheumatoid arthritis on work status and social and leisure time activities in patients followed 8 years from onset. J Rheumatol 1998;25:44-50.

26 Sokka T, Kautiainen H, Mottonen T, Hannonen P. Work disability in rheumatoid arthritis 10 years after the diagnosis. J Rheumatol 1999;26:1681-5.

27 Mason JH, Simms, RW, Goldenburg DL, Meenan RF. The impact of fibromyalgia on work: a comparison with RA. Arthritis Rheum 1989;32(suppl):S46.

28 Eaker S, Bergström R, Bergström A, Adami H-O, Nyren O Response rate to mailed epidemiologic questionnaires: a population-based randomized trial of variations in design and mailing routines. Am J Epidemiol 1998;147:74-82.

29 Symmons DPM, Barrett EM, Bankhead CR, Scott DGI, Silman AJ. The incidence of rheumatoid arthritis in the United Kingdom: results from the Norfolk arthritis register. Br J Rheumatol 1994;33:735-9.

30 Wolfe F, Ross K, Hawley DJ, Roberts FK, Cathey MA. The prognosis of rheumatoid arthritis and undifferentiated polyarthritis syndrome in the clinic: a study of 1141 patients. J Rheumatol 1993;20:2005-9.

31 van Jaarsveld $\mathrm{CH}$, Jacobs JW, Schrijvers AJ, van AlbadaKuipers GA, Hofman DM, Bijlsma JW. Effects of rheumatoid arthritis on employment and social participation during the first years of disease in the Netherlands. Br J Rheumatol 1998;37:848-53.

32 Yelin E, Meenan R, Nevitt M, Epstein W. Work disability in rheumatoid arthritis: effects of disease, social and work factors. Ann Intern Med 1980;93:551-6.

33 Fifield J, Reisine ST, Grady K. Work disability and the experience of pain and depression in rheumatoid arthritis. Soc Sci Med 1991;33:579-85.

34 Reisine S, McQuillan J, Fifield J. Predictors of work disability in rheumatoid arthritis patients. Arthritis Rheum 1995; 38:1630-7.

35 Allaire SH, Anderson JJ, Meenan RF. Reducing work disability associated with rheumatoid arthritis: identification of additional risk factors and persons likely to benefit from intervention. Arthritis Care Research 1996;9:349-57. 